\title{
Editorial 2017 - V.15, N.1 (Jan-jun)
}

O primeiro semestre de 2017 foi um importante momento para a equipe da Revista de Ensino de Bioquimica, decorrente dos preparativos para o primeiro prêmio Nacional de Ensino de Bioquímica e Biologia Molecular Bayardo Baptista Torres que será entregue durante a $46^{\circ}$ Reunião Anual da SBBq em Águas de Lindóia-SP, além das atividades propostas para o evento pela equipe da revista, incluindo seminário, simpósio e minicursos na área de ensino.

Tivemos três publicações na seção "Pesquisa em ensino". A primeira abordando a potencialização no ensino de Fisiologia a partir de discussões em fóruns online no ambiente virtual Moodle, indicando melhorias nos processos de ensino-aprendizagem. A segunda abordando um mapeamento das tendências na área de ensino de Bioquímica, a partir dos resumos publicados nos anais das reuniões anuais da SBBq entre os anos de 2006 e 2016, apresentando dados descritivos e exploratórios para criação de um panorama do período. A terceira publicação desta seção focou nas dificuldades na aprendizagem de Bioquímica por alunos em uma universidade federal, destacando também as dificuldades em conhecimentos prévios ao ensino superior e pré-requisitos para a compreensão dos conceitos Bioquímicos.

A seção "Inovações Educacionais" contou com uma publicação abordando a importância das atividades experimentais nas séries iniciais do ensino fundamental, destacando a importância da abordagem das questões científicas desde a formação inicial dos estudantes.

Na seção "REB na Escola" tivemos uma publicação abordando o ensino-aprendizagem de conceitos de Imunologia, presentes no $5^{\circ}$ ao $8^{\circ}$ ano do ensino fundamental, por meio de jogos RPG (Role Playing Game), o que gerou grande motivação no estudantes.

De forma sintética, observamos o crescimento na REB das publicações de temáticas correlacionadas com a Bioquímica e que aparecem tanto no ensino básico, quanto no superior, valorizando esta integração entre áreas para a compreensão dos processos nos seres vivos e trazendo resultados de inovações e pesquisas que podem contribuir para a melhoria nos processos de ensino-aprendizagem.

Atenciosamente,

Gabriel G. Hornink Vera Maria T. Trindade Eduardo Galembeck Bayardo B. Torres Unifal-MG UFRGS Unicamp USP 